\title{
Fewer Young Adults Lack Health Insurance Following Key ACA Provisions
}

\author{
Jessica A. Carson
}

? The share of people without health insurance has dropped dramatically since the implementation of the Affordable Care Act (ACA), but declines have been most dramatic among young adults age 19 to 25. In 2008, one-in-three 23 -year-olds were uninsured, likely reflecting their graduation from college and therefore, their ineligibility to be covered on parental plans. Beginning in 2010, the ACA allowed young adults to remain on their parents' plans until age 26; the orange line in Figure 1 reflects this shift, as 26-year-olds, rather than 23-year-olds, became the most often uninsured by 2013.

Although 26-year-olds are still the most likely to be uninsured in 2016, the effects of the individual health insurance mandate and the opening of the health insurance marketplaces in 2014 are evident in the declining share without coverage (from 30 percent to 17 percent). In 2016, young adults in rural places are uninsured at higher rates than those in urban places (17.0 percent versus 14.0 percent), as are young adults in states that did not expand Medicaid (21.0 percent versus 10.8 percent in expansion states). As the health insurance landscape continues to shift, policymakers should consider how to support young adults in their transition into adulthood by providing options for affordable, accessible insurance for students and for workers in jobs without benefits.

\section{FIGURE 1: PERCENT UNINSURED BY AGE, 2008, 2013, \& 2016}

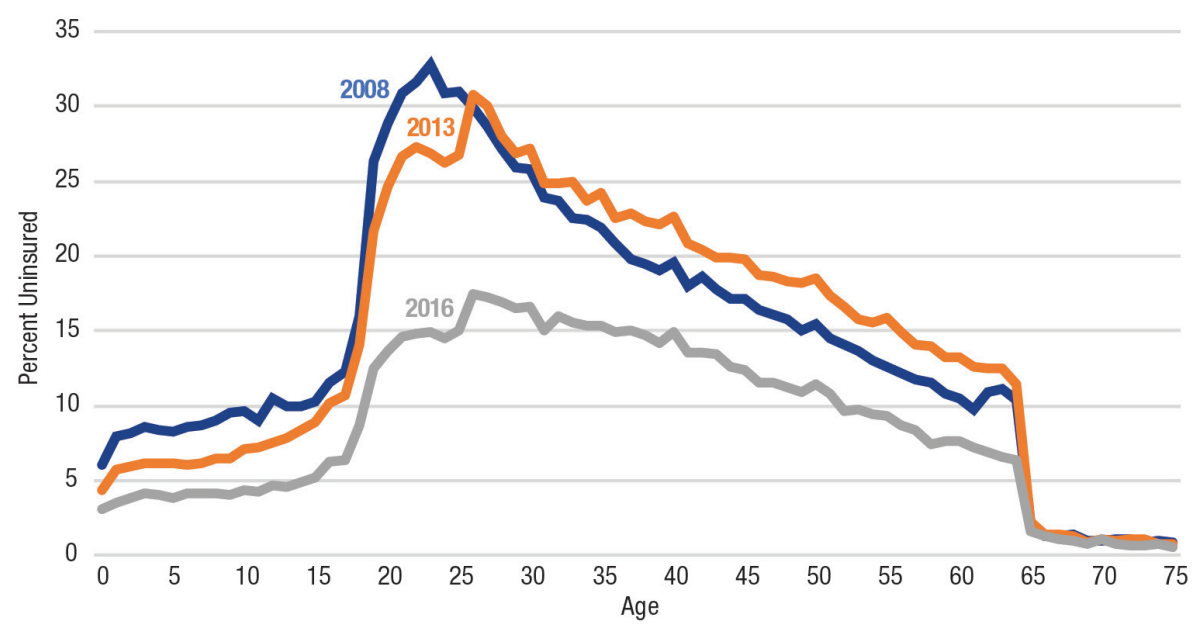

Note: This figure updates one previously produced by the Census Bureau's Random Samplings blog. Source: American Community Survey, 2008, 2013, 2016

\section{ig9}

The Patient Protection and Affordable Care Act was signed into law in 2010 and included multiple provisions, phased in over time, with the goal of expanding access to health insurance and lowering the costs of health care.
See related publications at carsey.unh.edu

- The Impact of State Medicaid Expansion Under the Affordable Care Act on Health Insurance Coverage at the County Level (December 2016)

- Health Insurance Among Young Adults Rebounds Post Recession (October 2014)

This analysis was made possible by funding from the Annie E. Casey Foundation. 